\title{
What if We Were Twice as Close to the Sun?
}

\author{
Findings from a Science Summer Camp Serving Underrepresented Youth
}

\author{
Sherry Yi \\ Educational Psychology \\ University of Illinois \\ Urbana-Champaign, Illinois, USA \\ fangyi1@illinois.edu
}

\author{
H. Chad Lane \\ Educational Psychology \\ University of Illinois \\ Urbana-Champaign, Illinois, USA \\ hclane@illinois.edu
}

\author{
Ömer Delialioğlu \\ Computer Education \& \\ Instructional Technology \\ Middle East Technical University \\ Ankara, Turkey \\ omerd@metu.edu.tr
}

\begin{abstract}
Diversity has been a prevalent issue in the American STEM workforce for a number of years. Efforts to increase diversification have resulted in alternate learning spaces such as makerspaces, after school programs, and technology integrated curriculums. Our study, hosted at a non-profit organization serving underrepresented youth, leveraged the video game Minecraft $(M C)$ as a way to engage summer campers in scientific concepts and inquiries over one week. Reoccurring themes from interviews include familial rules on technology use at home, engaging with STEM in a novel way, and a love for building and creating within $M C$. We discuss our insight into the discoveries and challenges of these types of STEM-oriented program that takes place in informal settings.
\end{abstract}

\section{CCS CONCEPTS}

- Social and professional topics Informal education - Social and professional topics Race and ethnicity - Social and professional topics Adolescents - Applied computing Interactive learning environments • General and reference Experimentation

\section{KEYWORDS}

Diversity, informal learning, STEM education, triggering interest, Minecraft, video games, situational interest

\section{ACM Reference format:}

Sherry Yi, H. Chad Lane and Ömer Delialioğlu. 2018. What if We Were Twice as Close to the Sun? Findings from a Science Summer Camp Serving Underrepresented Youth. In Proceedings of ACM Foundations of Digital Games conference (FDG'19). ACM, San Luis Obispo, CA, USA. https://doi.org/10.1145/3337722.3337762

Permission to make digital or hard copies of all or part of this work for personal or classroom use is granted without fee provided that copies are not made or distributed for profit or commercial advantage and that copies bear this notice and the full citation on the first page. Copyrights for components of this work owned by others than ACM must be honored. Abstracting with credit is permitted. To copy otherwise, or republish, to post on servers or to redistribute to lists, requires prior specific permission and/or a fee. Request permissions from Permissions@acm.org.

$F D G$ '19, August 26-30, 2019, San Luis Obispo, CA, USA

(C) 2019 Association for Computing Machinery.

ACM ISBN 978-1-4503-7217-6/19/08...\$15.00

https://doi.org/10.1145/3337722.3337762

\section{Introduction}

According to the National Center for Education Statistics, about $17 \%$ of the 1.8 million bachelor's degrees awarded to U.S. citizens were in STEM fields in 2013-14 [1]. Yet policy makers, administrators, education practitioners, and more continue to pour countless hours in exploring ways to promote diversity in the field of science, technology, engineering, and mathematics (STEM). It is predicted that by 2020, 65\% of all jobs in the United States will require a post-secondary degree associated with STEM [2]. However, numbers continue to show a deficiency in the diversity in the American STEM workforce, particularly the lower rates of STEM degrees awarded to Black, American Indian/Alaska Native, Hispanic, and Pacific Islander students and for those who identify as female [1, 3, 29]. One way to market the field of STEM and appeal to future generations is to leverage existing entertainment technologies such as video games. Consumer spending on the video game industry totaled $\$ 25.1$ billion in 2010 , more than the music industry and almost double the amount of box office movies [4]. A 2002-03 survey drawing from a nationally representative sample in the US showed that gamers (ages 10-19) on average played an hour on weekdays and an hour and a half on weekends [5]. Technologies have different effects depending on how they are situated within specific contexts [6] and video games are no exception. We seek to contribute to this literature by asking the following research questions: Does our intervention using a sandbox game alongside a science curriculum help raise interest in STEM? What are the factors influencing participants' interest in STEM outside of camp?

\section{Background}

Situational interest. Researchers often point to two main types of interest: situational and individual. Situational interest often refers to subject matter, specific experiences, and their contextual features. It tends to be spontaneous and may or may not continue. Individual interest, on the other hand, focuses on individual differences and is usually long-lasting and representative of an emotional investment by the learner [7, 30]. We focus on situational interest in this paper, although we remain committed 
in our future work to exploring the important links to individual interest that may emerge. While there are different theoretical models on the triggering and maintenance of interest that exist [8], we chose to utilize Hidi \& Renninger's four-phase model [9]. Their proposed model of interest phase begins with triggered situational interest, followed by maintained situational interest, and if the interest is sustained it becomes emerging developed individual interest, and finally well-developed individual interest. They maintain that progression from one phase to another requires support from others (e.g., parents, teachers, peers), and any individual can regress to a previous phase, or have the interest disappear entirely. Situational interest involves a person-object relationship, or the specific relationship between an individual and a topic or content in their environment [10]. Situational interest has also been repeatedly associated with 5 dimensions: novelty, challenge, attention demand, exploration intention, and instant enjoyment $[11,12]$.

Utilizing video games. Many modern video games provide connections to STEM. The use of video games may represent an opportunity to attract more diverse candidates in the STEM field by means of triggering interest in the subject [14]. Interest was identified as the most common factor for persisting in STEM across both males and females who majored in STEM during college, and this interest increases over time [3]. Interest has a powerful impact on the way one perceives the world and on one's attitude towards a specific topic [7, 8, 10, 11, 13-15]. Another quality of interest is that it is elusive; it can be triggered without the person knowing of its occurrence, and reoccurring engagement with the subject is needed to sustain interest $[8,9]$. Video games act as a suitable medium to trigger interest in STEM since the platform is culturally relevant, widely used, and allows for repeated engagement. In our study, we use the sandbox game $M C$ as the vessel to trigger situational interest and engage adolescents in STEM topics. In contrast to traditional games, $M C$ does not have an end-goal or direct way to "win" the game. Game mechanics allow the player to decide on what and how she wants to spend her time in the virtual world with activities ranging from hunting monsters to decorating a dream house, and the game visually resembles blocks of Legos [16]. Similar studies have been conducted utilizing $M C$ during summer camps including ways to promote interest in computer science [17] and exploring issues of equity and technology access through such programs [18]. Surprisingly despite $M C$ s raved acceptance as a popular summer program for middle schoolers [18, 19-22], there are not many studies that capture the processes of such camps and the occurrences within them as we have outlined here.

\section{Methods}

All participants were enrolled in one $M C$ centered program during one of two summer sessions; each session lasted one week. The program ran for five weekdays for a total of 25 hours per week. Learning activities include technical tutorials, lecture, discussion, guided explorations within the game and free time to work on individual or group projects; no grades were assigned for these activities. We referred to hypothetical scenarios of Earth speculated by astrophysicist Dr. Neil Comins [31, 32], a co-PI on this project. Participants were asked to take a survey on interest in $M C$ and STEM interest on the first and last day of camp. The $M C$ interest survey is a 60-item Likert scale survey (a large smiley face representing "strongly like" and progressively less contented faces ending on a tongue out emoticon representing "strongly dislike") we devised that pull from a representative sample of items from the $M C$ action taxonomy [33]. We used the validated Student Attitudes toward STEM survey (S-STEM) developed by Faber et al. [34] that tries to capture the attitudes towards STEM and $21^{\text {st }}$ century earning skills of middle school and early high school students. Part 1 of the survey focuses on self-efficacy beliefs in math, science, engineering/technology, and $21^{\text {st }}$ century skills (e.g., "I am confident I can set my own learning goals"). Part 2 of the survey asks about future interests of the learner, providing short descriptions of 12 STEM-related fields (e.g., physics, biology, medicine, earth science) and participants rate their interest from 1-4 on how interested they are to learn more about the field. Near the last two days of camp, we interviewed participants about their experience of the camp, school, and video game play habits. Two researchers from the team took fieldnotes throughout each day of camp, one noting on specific times and occurrences of the camp and the other focusing on the content being discussed (though neither were restricted to one or the other and there was some overlap), and at the end of the day the notes were combined into one document after the two researchers reviewed the others' notes. This allowed room for clarifications and confirmation on described events. We approached the project using both quantitative and qualitative methods, however for the purpose of this paper we focus on the latter.

3.1 Participants. We partnered with a non-profit community center serving underrepresented populations in a small Midwestern university town. $M C$ was used in the camps to play in creative mode, explore hypothetical versions of earth, and learn in-game or third-party manipulations (e.g., how to teleport from one place to another). The sample consists of 22 participants ages 10-13 $(M=11.909)$ and $9(41 \%)$ males. Ethnicities were selfreported as 14(64\%) Black or African American, 2 (9\%) biracial, and 6 (27\%) unknowns (i.e. incomplete surveys). The camp is constructed around principles of science and astronomy, the main activity being the exploration of what-if hypothetical worlds through sandbox games supplemented by short science presentations lasting no more than 10 minutes. Each science lecture focused on characteristics of an alternate version of Earth (e.g., if Earth had no moon) and the scientific reasoning behind why certain phenomena occur (e.g., why the color blue indicates the hottest temperature of a planet). Students were encouraged to ask questions during and after the lectures.

3.2 Procedure. We ran one-week camps over the course of 2 weeks with two different groups. The camps were optional sign-ups exclusive to the community center's summer program and was advertised as a $M C$ - and STEM-focused option and needed both consent of parent and child. Priority entry to the camp was given to students who were in middle grades. Participants were sorted 
randomly into two groups, week 1 and week 2 . We decided to use both a survey and group interviews to better capture a holistic narrative of the camp and more accurately understand what development had occurred. We followed a timeline for both camps with most days ending in free time to build and explore our server. Each day revolves around a specific hypothetical world, and the scientific implications of such world are supplemented by brief science lectures from the research team. Campers were encouraged to ask for clarifications, ask questions, and engage in conversation throughout lectures.

$\begin{array}{ll}\text { Monday } & \begin{array}{l}\text { Introductions, customize } M C \text { avatars, } \\ \text { orientation to our } M C \text { server, exploration } \\ \text { of Earth and comparing to Earth with no } \\ \text { moon in } M C \text { mini-science lecture, }\end{array} \\ \text { Tuesday } & \begin{array}{l}\text { WorldPainter tutorial } \\ \text { Recap of Earth with no moon, } \\ \text { exploration of colder sun, mini-science }\end{array} \\ & \begin{array}{l}\text { lecture, free time to build and explore on } \\ \text { colder Sun, WorldPainter tutorial }\end{array} \\ \text { Wednesday } & \begin{array}{l}\text { STEM survey, mini-science lecture, } \\ \text { exploration of tilted Earth and }\end{array} \\ \text { Thursday } & \begin{array}{l}\text { comparing to baseline Earth, campers } \\ \text { devise their own "what-if" question }\end{array} \\ \text { Friday } & \begin{array}{l}\text { Building houses on hypothetical worlds } \\ \text { More time to build followed by a show- } \\ \text { and-tell in front of the whole class }\end{array}\end{array}$

3.3 Minecraft. Our server features a main "hub" where anyone who enters can access portals that teleport to Earth in the following conditions: 1.) normal baseline Earth, 2.) Earth with a different tilt, and 4.) Earth with a cooler Sun. Portals were color coded to ease navigation of the entire group (e.g., the instructor could say, "Everybody go to the red gate!"). We designed the maps to encourage exploration of each terrain and to create a sense of adventure, thus we decided on using an aircraft as means of transporting between different spots on a single map. This was particularly important to highlight how vastly different the terrain can differ within one planet, and to raise questions from participants on the conditions that can or cannot sustain life. These world explorations are supplemented by short science lectures about each world. For example, the lecture on colder-Sun explains why a planet's color emission is counterintuitive; red-hot actually means that the planet is much cooler, whereas the hottest glow on the sun emits a blue-green color. Following lectures, campers were asked to write out scientific observations on wooden signs, a preexisting object in the game commonly used to denote a message to other players. After campers are prepped with knowledge about $M C$ and ways to build and manipulate within the game, we ask them to form their own "what-if" hypothetical questions.

3.4 Interviews. Campers were asked on day 4 or 5 to participate in a 1-on-1 (3 cases) or paired (18 cases) semi-structured interviews that lasted from 15- to 30-minutes. Semi-structured interviews are regarded as informal but guided [24,25], the first matching the environment of the learning center and the latter serving to our research inquiries. Semi-structured interviews also serve to collect descriptions of the interviewee's perceptions with respect to interpretation of the meaning behind such descriptions [26]. In other words, semi-structured interviews provided us an opportunity to gain deeper insight into how participants perceive our $M C$ program and shed light on their understandings of science concepts. We were aware that our presence was completely new to participants and that participants may not have had prior experience working with researchers. Therefore, we decided to conduct paired interviews to account for social desirability bias and attempt to put participants at ease [25]: one researcher was male and the other female, and we took turns leading the interviews depending on how we expected participants to interact during conversation. For example, when the paired participants are female, the female researcher took the lead on interviewing. Those who were asked to participate in 1-on-1 interviews were either missing consent for audio recording or researchers encountered an odd number of campers on that particular day. Questions centered around STEM-related aspects of play in $M C$, feelings toward STEM subjects in school, personal preferences when it comes to gameplay, and connections between $M C$ and the real world. The last portion of the interview focused on astronomy knowledge, which tested the effectiveness of our hypothetical worlds and lecture series. A sample of our questions include:

- How often do you play video games? Tell me 3 games that you like the most and 3 you don't like.

- Was there anything cool you saw in $M C$ and thought it would be great to have in the real world? Why?

- Can you tell me about the Moon? How does it affect us here on Earth?

\section{Results}

We interviewed as many participants as time and schedule allotted in a separate room away from the noise of the main activity room. We first interviewed voluntary subjects one-onone, then noticing the discomfort of participants, proceeded to interview subjects in pairs; there were two researchers and two subjects in the room at a time with all chairs facing inward. Participants were paired based on age and gender; we tried to make them as homogenous as possible after we found that an age mismatch between one pair disrupted more than contribute to the flow of conversation. Candy was available to participants at the end of the interview but was not advertised prior to the interview.

4.1 Family Rules on Technology Use. Out of the 21 interviewed campers, 13 reported some type of restrictions on technology use at home. Usually, time spent using technology were controlled by parents. A total of 2 campers reported that if they disobeyed this rule, the consequence would be getting their phone taken away. A total of 4 campers could not use their phones after a specific cut-off time in the evening set by a parent. Other restrictions include the requirement finishing homework or chores prior to playing games (3 cases). Some had designated technology off-limit areas, such as in the car, at the dinner table, or anytime outside the home, in attempt to encourage conversations in-between 
family members (3 cases). One reported having no access to Internet at home, which isolated the camper from playing with friends online, and 3 campers claim having no rules or restrictions on technology use at home.

4.2 Engaging with STEM topics through digital play. Redstone is the $M C$ equivalent of electricity [16], making functional products like an automatic door or a large-scale calculator possible, and follows logical rules. In our tutorial, we taught campers how to light up redstone torches and encouraged campers to build on different ideas (e.g., one camper decided to build a rollercoaster that drops the rider into a pit of lava). "I liked the when we did the redstone the other day, that was really cool cause like I've never learned anything with redstone before," said 423. Playing with redstone enabled campers to interact with concepts of engineering and technology and experiment with powering machines. We witness one instance of connecting the idea of redstone to public service in the real world:

403: They should make, what's it called, like the redstone? They should make those [...] I feel like you know how [PI on the project] was doing that light stuff? He should they should make that. Like for like for the people that don't got homes. Cause they can't see in no dark and stuff.

4.3 Love for Building. The level of familiarity and experience with $M C$ impacted the complexity of structures built but did not impact the desire to build and create. We observed that those who were well-versed in $M C$ prior to camp were able to more easily build elaborate structures (e.g., a simple one-story house consisting of two different materials or blocks versus using a variety of materials, colors, and so on). Novices often sought help from more advanced players who were available in their proximity or raise their hand to ask an instructor about game mechanics (e.g., how to teleport, how to build and mimic real-life objects). Participants who did not attend the camp regularly and found themselves unable to proceed within the game solely relied observations from the research team and their direct intervention, and by the end of the week those types of participants have either dropped the camp (there were other concurrent camps available) or did not consistently attend camp. The occurrence of building was largely unprompted and often took priority over our planned activity, such as making scientific observations of each planet. We tried to utilize the desire to build by prompting participants to think about the environment they inhabited. For example, Figure 1 was a response to our question, "What sort of house would you need in order to survive on this planet?"

"I love to build any houses. I can go the poor man's house with just like eight dirt blocks all the way to a giant mansion if you give me time," said 401. 401's sentiment for building houses was reflected in the sample. "I like building my house, that's the thing I put the most effort into," said 412. Throughout the two weeks of camp, many chose to build structures over any other $M C$-related activity. When time permitted during the interview sessions, we asked campers about their favorite thing to build in $M C .13$ of the 21 interviewed campers claimed that building houses, ranging from caves and wooden cabins to extravagant mansions, was their favorite $M C$ activity. 2 campers reported building a city or town as their favorite activity, and only 1 reported killing Creepers - the game's infamous explosive monster - as their favorite activity.

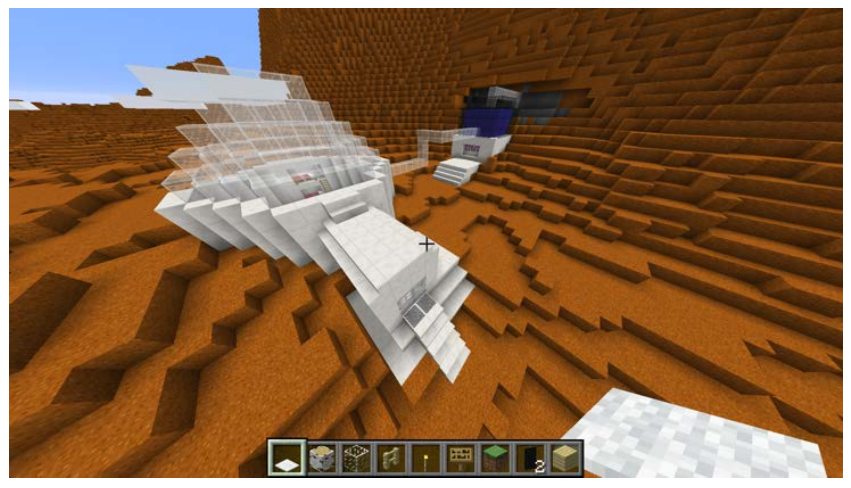

Figure 1: A house meant to withstand high pressures, complete with an airlock entrance ("Don't get lazy in the airlock!” warning sign) and an indoor vegetable garden.

4.4 Science misconceptions. We asked campers hypothetical science questions during the last two days of camp to gauge their understanding of the scientific concepts discussed and taught during days prior. 22 science misconceptions from 12 campers were cataloged from our interviews and sorted into the following categories, followed by the number of occurrences from most to least: simple cause-effect interpretation (9), misunderstanding of mutual and/or basic motion of a planet (e.g., moon, earth, sun, earth) (5), misunderstanding of relative motion (5). Simple causeeffect interpretations highlight, as the name implies, using cause and effects to rationalize how the world functions. For example, when asked what would happen to earth if it was closer to the sun, 401 responds, "There will be rapid fire." Other campers provide similar answers during separate interviews. 406: We would all burn. It would be hot. [There would be] no more life? 427: It would probably be lit on fire if it was it were to be closer we would probably burn up and die. These campers illustrate the logic behind cause and effect: the sun is hot and on fire, therefore being closer to the sun means being closer to a hot surface and increasing chances of catching on fire. Another misunderstanding was on planet motions and relative motion. 402 believed that the Sun caused daytime and nighttime instead of crediting earth. 401 reported that people would cease to exist if there was no moon, because "there would be no gravity." We also asked participants to speculate on events that would occur if the earth were to stop rotating:

418: Things would start falling off. Earthquakes would happen. Things would die because there's no wind. 427: It will turn into like a oval if it weren't tilted, right? Like the course would turn into an oval. And then I think it will be like more wide on the axis. 
4.5 Undervaluing science and social science. We encountered an unusually talkative pair in contrast with majority of other pair interviews. The campers had a fairly large age difference between them considering cognitive developments, 409 at age 10 and 410 at age 13. They often rambled on one topic and built arguments off of one another, 410 often challenging what was being said by 409. Unlike the other campers who all attended public school, 409 attended a private school. During one of the many deviations in our interview, 409 pointed strongly that the only necessity for knowing math is if one aspires to become an engineer. 410 follows this by undervaluing the social sciences:

What you gone do, study some [biology], what are you going to do? Study some rocks that are at or get that were a few days ago. The only time you'll need social studies is when you was like, when you're trying, when you're correcting a person on what they said wrong.

Both 409 and 410 connect a science topic to a clear underlying motivation; according to their logic, a person does not have any use for learning these science topics unless he or she had clear intention of using said topic (e.g., to become an engineer or to show off at a dinner party). It is unclear from our interview how 409 and 410 came to these conclusions, whether they were influenced from opinions at home, at school, or how they arrived at these conclusions on their own.

4.6. Reaching those who dislike MC. On the first day of camp, 404 (13-year-old female) confronted the research team that she had no reason to learn science; she was going into the beautician industry, and further, she had no interest in $M C$ and preferred games like Grand Theft Auto. A researcher countered that dyeing hair required knowledge about chemistry and working a business required math, but those comments were dismissed. The remainder and the following day followed a similar pattern: 404 had no interest in participating in the camp or learning about science. However, when we started to teach participants how to use WorldPainter, her face lit up and worked on building a beach extensively. She did not return to this project the next day. In an interview, she reports that WorldPainter was her favorite part of camp. This does not indicate an increased interest in STEM but suggests that it is possible to trigger interest in this type of $M C$ activity in those who indicate little to no interest in $M C$ itself. Another example is 410, who remained either disruptive or unengaged throughout the first days of camp but became absorbed in $M C$ once we introduced redstone into the curriculum. To our surprise, building with redstone was 410's favorite activity. Our explanation, based on observation, is that 410 already understood the basics of MC which was emphasized in the beginning of camp to equalize the learning curve for all campers. In other words, 410 experienced boredom and restrictions from our set schedule, but the challenge of redstone triggered his interest its mechanic and the game.

\section{Discussion}

$M C$ proved to be successful in engaging the majority of campers throughout the program and showed potential to trigger situational interest in those who have no or little interest in $M C$ prior to camp (refer to the example with 404). This suggests that sandbox video games can be used trigger interest in specific topics given that there are supplemental lessons through other means (e.g., PowerPoint, work sheets, textbooks). $M C$ proved to have the five dimensions associated with situational interest [11,12], including novelty (exploring new planets), challenge (presented by instructors or suggested by peers), attention demand (using a video game platform that appeals to adolescents), exploration intention (guided and actively encouraged by instructor), and instant enjoyment (participants choosing to stay indoors and play $M C$ over playing outside). The majority of campers seem to rely on parental figures to manage time spent on technology. Not every camper owned the $M C$ software, had Internet access or had access to the computer at home, and therefore the chance to tinker and play with the program with friends during camp was appealing. About 3-4 campers on average per week chose to stay inside and play $M C$ instead of spending their break time outdoors. Campers often encouraged each other to complete against one another, whether it was based on who could build the biggest mansion or make the most explosions in-game:

406: Oh, I'm having real fun with this TNT. [He blows up a large section of stacked TNT blocks.] It blows you away?

407: Let's see who can build the most TNT.

This was true for campers within a wide range of experiences, from complete novices to advanced players. Our presence at the community center stood out from the other simultaneous camps for these reasons: 1) we occupied a newly renovated space upstairs, 2) our advertisement included MC, an untraditional method at the community center, and 3) we utilized newly installed Internet connections and laptops from the local makerspace. Half of the research team met campers on the dayof, and as expected our connections with students had to be earned. We were challenged by a short amount of time to bond with participants and resorted to using candy as a reward system for desired behavior (e.g., raising their hand, picking up trash, giving the presenter their attention) on day 2 of our first camp and it proved effective, and we instilled this reward system throughout the remaining duration of both camps. The majority of participants were engaged during science lectures, putting forth their own hypothetical questions such as, "What if the black hole was a white one?" and "What if the world split apart?". We also learned that the campers greatly enjoyed customizing their avatars during week 1 , and we dedicated time both in week 1 and 2 for this well-received activity. Working with redstone seems to have attributed interest in figuring out machines work and the joy in creating new products as campers were able to tinker with not only the redstone material, but redstone in combination with other available resources in-game (e.g., creating a light switch connected to a functional light). The inclination for building structures is supported by the in-game ability to build any structure imaginable and lessons on redstone and astronomy, though the long-term impact of the camp on participants' science knowledge is unclear and requires further data collection. Our 
data is consistent with past research [21] and suggests that those who had prior interest to science were able to build on existing knowledge by engaging in video game technology, a contemporary way of thinking about a problem, instead of testing one theory against data. Those who did not show interest in science were more prone to report the identified misunderstandings of science topics. We cannot rule out the possibility that some participants may not have been exposed to the foundations of the scientific concepts we selected or that some participants did not have prior chances to engage with science concepts using technology.

\section{Limitations}

We faced a data collection setting vastly different from a lab, and our experience is similar to those encountered in previous research [18] in addition to us running the program itself (not just observing). We were fortunate enough to have partnered with FabLab who set up the entire space and worked with us to ensure all machines were up-to-date and could run the necessary software programs ahead of time, and fortunate to have our technical team on standby and resolved unexpected server-related issues as they occurred, as well as members physically present who handled Internet-related issues. Overall, our $M C$ camp had 52 interested students, 24 of which we had research consent, and 16 of whom completed our survey in its entirety. The incomplete surveys account for our unknowns in demographics. The $M C$ camp coincided with the campers' summer vacation. Some campers compared our program to summer school, some reported their parents signing them up without them knowing or having misconceptions that our camp was free time to play $M C$. In addition, our program was contrasted with other simultaneous programs that involved trips to the local pool. This conflict caused some initial resistance within a few campers, but by the second day the majority were willing to explore our crafted worlds on their own and participate (or at least sit quietly) during activities related to science learning.

We experienced first-hand the fast and dynamic environment at the community center. There was no guarantee on the daily attendance of any participants, and the everchanging schedules proved collecting both pre- and post-surveys a challenge. Despite each day being divided into blocks of time dedicated to wellthought out activities, campers frequently dropped or added programs last-minute, were picked up early on random days without warning, or attended only one day of camp. These events happened randomly and with little warning, and we faced difficulties accounting for the attendance of campers. We were also informed that the summer invited students to join programs from out-of-town, whereas in the school year there is much more consistency in attendance. It is possible that camper responses would be more positive if the camps were implemented during the academic year, though the reason why we initially decided to conduct our research in the summer is to lessen the pressure and burdens on students as they are bombarded by regular schoolwork and classes. Our experience and those of similar studies [13] provide insight into the dynamics of the environment and hurdles that must be faced when trying to reach marginalized populations in the community using technology-focused programs.

\section{Conclusion}

The key takeaways from our experiences in conducting this study are summarized below:

- Our findings suggest that sandbox video games have the potential to trigger situational interest in science and astronomy by providing an accessible virtual environment paired with guided instruction.

- $M C$ can be a way for adolescents to interact with STEM topics in a digital environment. This is especially important for adolescents who may not be exposed to these topics otherwise.

- To state what may sound rather obvious, the audience for educational technologies should be considered prior to its implementation. For example, does most of the audience understand how to use a mouse and keyboard or are they used to the functions on a touchscreen?

- Implementing educational technology is a time-intensive effort. How much time is the educator and/or instructor able to dedicate in learning the technology? Is there support in implementing such efforts?

It is our hope that the provided timeline and content of the camp may serve as a reference to other educators interested in incorporating video games into their curriculum or program. We are currently working on making our MC program publicly available on our project website [28] in conjunction with downloadable class content for instructors and/or parents. It is important to emphasize that participant ages ranged from 10- to 13-years-old, the age in which the majority of adolescents begin to develop cognitively [27]. Much of the observed interactions during camp involved one participant looking towards another for how she or he should behave; participants sought peer approval more than instructor approval. The biggest indicator was the contrast between how participants acted among peers and their behavior during interviews; participants that appeared bored or sleepy during camp acted attentive, polite, and more than willing to participate during paired interviews. There were times where we struggled to understand the underlying message of statements- thoughts, feelings, conceptualizations, and theoriesthat they could not yet put into words. Researchers are likely viewed as outsiders to the everchanging world of adolescents; we should tread cautiously when navigating such worlds and stay alert on ways adolescents may contradict their own statements without knowing and expose vulnerabilities with or without intention. Future research should explore the lasting effect of triggered interest and whether such summer programs can sustain interest in STEM topics through longer durations (e.g., a longitudinal study following the same participants over two years tracking interest development). Our results also shed light on the types of science misconceptions that may occur in underrepresented youth and suggest that MC and other sandbox games have the potential to serve as a novel way to interact with STEM topics. 


\section{ACKNOWLEDGMENTS}

We thank Dr. Neil Comins and Dr. Jorge Perez-Gallego for their contributions in astrological content and verifying the accuracy in our work. This study would not have been possible without the contributions of our team of coders- Hyunwoo Park, Jack Henhapl, and Aidan Rivera-Rogers- and great support from Dr. Jeff Ginger and his team at the FabLab. The authors would also like to thank anonymous reviews for their thoughtful feedback and patience. This material is based upon work supported by the National Science Foundation under Grant No. 1713609. Any opinions, findings, and conclusions or recommendations expressed in this material are those of the author(s) and do not necessarily reflect the views of the National Science Foundation. Ömer Delialioğlu was supported by the Fulbright Visiting Scholar Program by the Turkish Fulbright Commission for the enrolment of this research.

\section{REFERENCES}

[1] National Center for Education Statistics. Indicator 24: STEM Degrees. https://nces.ed.gov/programs/raceindicators/indicator_reg.asp

[2] A. Carnevale, N. Smit, \& J. Strohl, Recovery: Job growth and education requirements through 2020, https://cew.georgetown.edu/cew reports/recovery-job-growth-and-education-requirements-through2020/\#fullreport

[3] A.V. Maltese and C.S. Cooper (2017). STEM Pathways: Do Men and Women Differ in Why They Enter and Exit? AERA Open, 3(3), 1-16.

[4] S.E. Siwek, Video Games in the 21st Century: The 2010 Report, http://www.theesa.com/wpcontent/uploads/2017/02/ESA_EconomicImpactReport_Design_V3.pdf

[5] H.M. Cummings and E.A. Vandewater (2007). Relation of adolescent video game play to time spent in other activities. Archives of pediatrics \& adolescent medicine, 161(7), 684-689.

[6] Peter Lang (Ed.) 2007. Good video games+ good learning: Collected essays on video games, learning, and literacy (Vol. 27). Peter Lang Publishing, New York, NY. DOI: https://doi.org/10.3726/978-1-4539-1162-4

[7] S. Hidi (1990). Interest and its contribution as a mental resource for learning. Review of Educational research, 60(4), 549-571.

[8] K.A. Renninger and S. Hidi (2011). Revisiting the conceptualization, measurement, and generation of interest. Educational Psychologist, 46(3), 168184.

[9] S. Hidi \& K.A. Renninger (2006). The four-phase model of interest development. Educational psychologist, 41(2), 111-127.

[10] A. Krapp (1999). Interest, motivation and learning: An educationalpsychological perspective. European journal of psychology of education, 14(1), 23-40.

[11] K. A. Renninger, S. Hidi, \& A. Krapp (Eds.) 1992. The role of interest in learning and development. Lawrence Erlbaum. Associates, Hillsdale, The relation of interest to the motivation of behavior: A self-determination theory perspective. DOI: https://doi.org/10.4324/9781315807430

[12] A. Chen, P.W. Darst, \& R.P. Pangrazi (2001). An examination of situational interest and its sources. British Journal of Educational Psychology, 71(3), 383400.

[13] A. Krapp (1999). Interest, motivation and learning: An educationalpsychological perspective. European Journal of Psychology of Education, 14(1) 23-40.

[14] K. A. Renninger, M. Nieswandt, \& S. Hidi (Eds.) 2015. Interest in Mathematics and Science Learning. American Educational Research Association, Washington, Chapter 12. DOI: https://doi.org/10.3102/978-0-935302-42-4

[15] P.J. Silvia (2006). Exploring the psychology of interest. Oxford University Press, Oxford. DOI: https://doi.org/10.1093/acprof:oso/9780195158557.001.0001

[16] B.C. Fran and B.J. Patricia (Eds.). 20XX. Cognitive Development in Digital Contexts. Academic Press, Cambridge, Chapter 7. DOI https://doi.org/10.1016/B978-0-12-809481-5.00007-9

[17] C. Zorn, C.A. Wingrave, E. Charbonneau, \& J.J. LaViola (2013, May). Exploring Minecraft as a conduit for increasing interest in programming. In FDG (p. 352359).

[18] M.G. Ames and J. Burrell (2017). 'Connected Learning' and the Equity Agenda: A Microsociology of Minecraft Play. Proceedings of the 2017 ACM Conference on Computer Supported Cooperative Work and Social Computing, 446-457.

[19] B. Whitehouse, Specialty summer camps for kids on Long Island, http://www.library.illinois.edu.proxy2.library.illinois.edu/proxy/go.php?url=ht tp://search.ebscohost.com.proxy2.library.illinois.edu/login.aspx?direct=true \&d $\mathrm{b}=\mathrm{nfh} \& \mathrm{AN}=2 \mathrm{~W} 63008338126 \&$ site $=$ eds-live $\&$ scope $=$ site

[20] B. Alston, SGTC to offer two Minecraft Camps this summer, http://www.library.illinois.edu.proxy2.library.illinois.edu/proxy/go.php?url=ht tp://search.ebscohost.com.proxy2.library.illinois.edu/login.aspx?direct=true\&d $\mathrm{b}=\mathrm{nfh} \& \mathrm{AN}=2 \mathrm{~W} 6900057711 \&$ site $=$ eds-live \&scope $=$ site

[21] K. Bolus, Scranton finishes up STEAM camp, http://www.library.illinois.edu.proxy2.library.illinois.edu/proxy/go.php?url=ht tp://search.ebscohost.com.proxy2.library.illinois.edu/login.aspx?direct=true\&d $\mathrm{b}=\mathrm{nfh} \& \mathrm{AN}=2 \mathrm{~W} 62523967288 \&$ site $=$ eds-live \&scope $=$ site

[22] R. Campbell, Annual Camp SIP inspiring to students, http://www.library.illinois.edu.proxy2.library.illinois.edu/proxy/go.php?url=ht tp://search.ebscohost.com.proxy2.library.illinois.edu/login.aspx?direct=true\&d $\mathrm{b}=\mathrm{nfh} \& \mathrm{AN}=2 \mathrm{~W} 62091603777 \&$ site $=$ eds-live \&scope $=$ site

[23] H. Coolican (2017). Research methods and statistics in psychology. Psychology Press, London. DOI: https://doi.org/10.4324/9780203769836

[24] L. Gideon (Ed.). 2012. Handbook of survey methodology for the social sciences. Springer Science+Business Media, New York, Chapter 8. DOI: https://doi.org/10.1007/978-1-4614-3876-2

[25] S, Kvale (2008). Doing interviews. Sage, London, Chapter 1. DOI: https://doi.org/10.4135/9781849208963

[26] R. Driver and J. Easley (1978). Pupils and paradigms: A review of literature related to concept development in adolescent science students. Studies in Science Education, 5(1), 61-84.

[27] D. Fuhrmann, L.J. Knoll, \& S.J. Blakemore (2015). Adolescence as a sensitive period of brain development. Trends in cognitive sciences, 19(10), 558-566.

[28] What-if Hypothetical Implementations in Minecraft, http://whimc.education.illinois.edu/

[29] J.G. Cromley, T. Perez, \& A. Kaplan (2016). Undergraduate STEM achievement and retention: Cognitive, motivational, and institutional factors and solutions. Policy Insights from the Behavioral and Brain Sciences, 3(1), 4-11.

[30] G. Schraw and S. Lehman (2001). Situational interest: A review of the literature and directions for future research. Educational psychology review, 13(1), 23-52.

[31] N.F. Comins. 1993. What if the moon didn't exist? Voyages to earths that might have been. Interdisciplinary Science Reviews, 20(3), 263-264.

[32] N.F. Comins. 2010. What If the Earth Had Two Moons? and nine other thoughtprovoking speculations on the solar system. Martin's Press, New York.

[33] H.C. Lane, S. Yi, B. Guerrero, \& N. Comins. Minecraft as a Sandbox for STEM Interest Development: Preliminary Results. Workshop Proceedings of the 25th International Conference on Computers in Education, 387-397.

[34] M. Faber, A. Unfried, E.N. Wiebe, J. Corn, L.W. Townsend, \& T.L. Collins (2013). Student attitudes toward STEM: The development of upper elementary school and middle/high school student surveys. In the Proceedings of the 120th American Society of Engineering Education Conference.

[35] H.C. Lane and S. Yi, S. (2017). Playing with virtual blocks: Minecraft as a learning environment for practice and research. In Cognitive Development in Digital Contexts (pp. 145-166). Academic Press. 